\title{
Family social characteristics related to physical growth of young children
}

\author{
NIELS CHRISTIANSEN, JOSÉ O. MORA, AND M. GUILLERMO HERRERA \\ Harvard University and the Colombian Institute of Family Welfare
}

\begin{abstract}
Christiansen, N., Mora, J. O., and Herrera, M. G. (1975). British Journal of Preventive and Social Medicine, 29, 121-130. Family social characteristics related to physical growth of young children. Altogether 164 poor families who had children of normal and subnormal weight and height were studied in Bogotá, Colombia. Physical growth was found to be positively associated with expenditure on food, sanitary conditions in the home, mother's age, birth interval between surviving children, level of parental newspaper reading, aspirations for children, and socioeconomic status. Physical growth was negatively associated with crowded living conditions and family size. Only mother's age, family size, spacing of births, and sanitary conditions were related to weight and height, independent of socioeconomic status. Food expenditure, crowding, parental newspaper reading, and aspirations for children all reflected the influence of socioeconomic status upon physical growth. The findings emphasized the importance of within-class social differences as they affect the physical growth of young children.
\end{abstract}

Studies concerning the social ecology of children's physical growth have found a range of family social characteristics associated with the level of growth. These are family food expenditure and birth order (Wray and Aguirre, 1969); crowding of dwelling and sleeping conditions (Weir, 1952; Stoch and Smythe, 1967); sanitary conditions and personal hygiene (Stoch and Smythe, 1967; Cravioto et al., 1967); family size, spacing of children's birth, and total number of children in the family (Wray and Aguirre, 1969; Cravioto et al., 1967; Chase and Martin, 1970; Berry and Cowin, 1954); number of pregnancies (Pollit and Ricciutti, 1968); spacing of pregnancies (Chase and Martin, 1970); mother's age, parental newspaper reading and national versus tribal language (Cravioto et al., 1967); an absent or alcoholic father (Stoch and Smythe, 1967; Chase and Martin, 1970); employment of mother (Berry and Cowin, 1954); parents' attitude to religion and future expectations for child (Young, 1970). However, these studies have looked only at simple bivariate associations between individual social variables and a measure of physical growth (usually height or weight). As social characteristics do not typically exist in isolation, bivariate associations tell us little about the separate countribution of a specific social characteristic to differences in physical growth, independent of the relationship of other social variables to physical growth. In particular, it is known that socioeconomic status is related to both physical growth and numerous social characteristics of the family. It is not clear, therefore, if the relationship between any specific social characteristic and weight and height is simply a result of a general effect of social level, which is difficult to separate into effects of specific class-related characteristics, or whether social characteristics can be identified which have independent effects upon physical growth.

The purpose of this paper is to examine a number of social characteristics in relation to weight and height of children, independent of the effects of family socioeconomic status. 


\section{The Research Setting}

The investigation took place in poor neighbourhoods comprising a municipal health district in Bogotá, Colombia. Bogotá is a rapidly growing city of approximately three million inhabitants (expected to reach eight million by 1980). The city stretches along the side of the eastern cordillera of the Andes. The wealthy live in the extreme north, and the poor live in the south and on the fringes of the city. The health district in which the study took place lies in the extreme south. About 17000 families live there, with an average of about seven persons to a family. Although the dwellings here have been built over a period of 20 to 30 years, many of the families have moved to Bogotá from the countryside or other cities during the past 10 years. Families live mostly in 'inquilinatos'multiple-family dwellings where a family typically occupies a single room, and shares kitchen and bathroom facilities with other tenants. Families move frequently from dwelling to dwelling within the district but infrequently outside.

Studies in the district have shown that the men are semi or unskilled workers, and employment is unstable. The most common occupations are in building construction, and many work in service occupations as truck drivers, shoe repairmen, or waiters. A small minority of the wives work, mainly as domestic helps (Christiansen and Dragastin, 1971).

About $60 \%$ of the children suffer from weight and height deficits, largely in the mild to moderate range. Upper respiratory infections and diarrhoea are endemic and constitute the most frequent health problems among the children (Mora, 1971).

\section{METHODS}

The study sample was selected in the following way:

A survey was made of the health district to determine the structure of those families resident in the district. The survey was made by young women especially trained for the study. Sampling was done on a quota basis; after surveying 11876 families, 189 families - a sufficiently large samplewere found who met the selection criteria listed below.

Families were selected for study using the following criteria:

(a) Two children of the same sex, and of the same parents. These criteria were used because intersibling comparisons of tests of mental performance were planned (Cobos, Latham, and Stare, 1972). (b) Both children under 5 years of age, the younger children being less than 30 months old. Where $\mathbb{\Phi}$ more than two eligible children existed in the family, those nearest in age were selected; $\overrightarrow{\vec{F}}$ firstborn children were excluded.

(c) Where criteria (a) and (b) were met, scales $\frac{\bar{O}}{\bar{N}}$ and infantometers were taken to the home by $\vec{\nabla}$ car, and families were selected in which both $\varrho$ children were of the same nutritional status $\tilde{\omega}$ (normal or subnormal), as defined below.

A social survey of these selected families was $\overrightarrow{\vec{\omega}}$ made three months after the census, when the $\stackrel{\circ}{\circ}$ children were again measured and weighed in the $\bar{\Phi}$ district health centre. The state of nutrition at this stage was used for subsequent analysis so that the 0 social and physical measurements would be con-? current. Of the 189 families selected, only $164 \vec{N}$ underwent both anthropometric and social measure- $\vec{\circ}$ ment. These were the families included in the present analysis. The drop-out rate between the time $\vec{c}$ of the census and the social survey was less than $2 \%$.

The physical growth of the younger child wos related to the social characteristics of the families or

\section{MEASUREMENT}

Children were classified as subnormal in physical growth if they fell below $90 \%$ weight and $95 \% \frac{\mathrm{D}}{\circ}$ height for their age, compared with Colombian age/sex standards. These criteria correspond approxi-윽 mately to the third percentile of the Harvard Physical Growth Standards. At the time of sample selection, 77 children showed 'normal' physical growth and 87 were 'subnormal' according to the above criteria. By the time of the social survey, nine ${ }_{-}^{?}$ of the 77 normal children had dropped below the 3 . normal height limit. In correlation and regressioni analysis, weight and height percentages for age 3 standard for each child were used.

The social survey was carried out in the home, using a standardized interview schedule. Obser $-\frac{D}{0}$ vations on living conditions were made at the end of the interview. For five of the social characteristicso (socioeconomic level, sanitary conditions in the home, in parental newspaper reading, mother's social partici- ํํ pation, and mother's emotional status), multiple- $\omega$ item scales were constructed using principal com $<$ ponents analysis and factor scoring. Analysi showed the scales to have acceptable interna consistency and discriminant validity.

The scale for assessing the socioeconomic leveb was a combination of the following characteristics $\mathbb{D}^{\circ}$ monthly family income, father's occupational level $\underset{\mathbb{D}}{\stackrel{?}{Q}}$ 
father's education, monthly family expenses, mother's literacy (reading), and mother's literacy (writing). The items concerning expenses and literacy, not commonly used in measures of socioeconomic status, were included to improve the reliability of the socioeconomic differences that were measured, as mothers sometimes had difficulty in estimating father's salary, father's employment was often unstable, and the mother sometimes did not know her husband's educational level.

Using the factor score for socioeconomic status, families were classified in socioeconomic groups. Five categories were created with a factor score range of 1.0. It was also decided to divide the sample into upper-lower class and lower class groups, because comparison of the sample's family incomes with census statistics for the city of Bogotá indicated that the sample fell within these two social classes. As the mode of the distribution of factor scores fell approximately at the point between the two lower socioeconomic categories (1 and 2$)$ and the upper three categories $(3,4$, and 5$)$, the sample was divided into lower-lower class and upper-lower class groups at this point.

\section{RESULTS}

Age AND ANTHRopometric AND Social

Characteristics of THE SAMPLe

The age distribution of the children in the sample is shown in Table I. Most of them were in the second year of life, and $98 \%$ were between 6 months and $2 \frac{1}{2}$ years old.

TABLE I

AGE DISTRIBUTION OF THE SAMPLE IN MONTHS

\begin{tabular}{c|cc}
\hline Months & No. & $\%$ \\
\hline $0-5$ & 4 & 2 \\
$6-11$ & 26 & 16 \\
$12-17$ & 49 & 30 \\
$18-23$ & 36 & 28 \\
$24-32$ & 39 & 24 \\
\hline Total & 164 & 100 \\
\hline
\end{tabular}

TABLE II

DISTRIBUTION OF WEIGHT/AGE PERCENTAGE AND HEIGHT/AGE PERCENTAGE FOR THE STUDY SAMPLE

\begin{tabular}{ccc|ccc}
\hline \multirow{3}{*}{ Months } & $\begin{array}{c}\text { Weight/Age \% } \\
\text { No. }\end{array}$ & $\%$ & \multicolumn{3}{|c}{ Meight/Age \% } \\
\hline $90+$ & 68 & 41 & $95+$ & No. & $\%$ \\
\hline $80-89$ & 28 & 17 & $90-94$ & 51 & 42 \\
$70-79$ & 43 & 26 & $85-89$ & 32 & 20 \\
$60-69$ & 19 & 12 & $80-84$ & 7 & 4 \\
$50-59$ & 6 & 4 & $75-79$ & 5 & 3 \\
\cline { 2 - 5 } & 164 & 100 & & 164 & 100 \\
\hline
\end{tabular}

TABLE III

SOME BASIC SOCIAL CHARACTERISTICS OF THE SAMPLE

\begin{tabular}{ccc}
\hline $\begin{array}{c}\text { Monthly Family Income } \\
\text { (USA \$) }\end{array}$ & No. & $\%$ \\
\hline $17-33$ & 47 & 31 \\
$34-50$ & 48 & 31 \\
$51-67$ & 27 & 18 \\
$68-83$ & 17 & 11 \\
$84-99$ & 14 & 9 \\
Not known & 11 & -
\end{tabular}

\begin{tabular}{ccc}
$\begin{array}{c}\text { Monthly Food Expenditure } \\
\text { (USA 8) }\end{array}$ & \\
\hline $0-16$ & 26 & 16 \\
$17-27$ & 56 & 34 \\
$28-38$ & 31 & 19 \\
$39-55$ & 40 & 25 \\
$56+$ & 10 & 6 \\
Not known & 1 & -
\end{tabular}

Mother's Literacy (Reading)

$\begin{array}{lrr}\text { Completely or functionally } & 60 & \\ \text { illiterate } & 60 \\ \text { Literate } & 101 & 63 \\ \text { Not known } & 3 & -\end{array}$

No. of Persons

living in the Family

$\begin{array}{lrl}4-5 & 40 & 24 \\ 6-7 & 67 & 41 \\ 8-9 & 29 & 18 \\ 10+ & 27 & 17 \\ \text { Not known } & 1 & -\end{array}$

\begin{tabular}{crc}
$\begin{array}{c}\text { No. of Rooms } \\
\text { occupied by Family }\end{array}$ & & \\
\hline 1 & 109 & 67 \\
2 & 38 & 23 \\
$3-4$ & 16 & 10 \\
Not known & 1 & -
\end{tabular}

\begin{tabular}{ccc}
$\begin{array}{l}\text { No. of Persons } \\
\text { per Bedroom }\end{array}$ & & \\
\hline $3-5$ & 55 & 34 \\
$6-8$ & 76 & 46 \\
9 or more & 33 & 20
\end{tabular}

\begin{tabular}{lrr}
$\begin{array}{c}\text { No. of Persons } \\
\text { per Bed }\end{array}$ & \\
\hline $1-3$ & 2 & 1 \\
$2-3$ & 94 & 58 \\
4 or more & 67 & 41 \\
Not known & 1 & -
\end{tabular}

\begin{tabular}{lrr}
$\begin{array}{c}\text { Mother's Age } \\
\text { (years) }\end{array}$ & \\
\hline $15-20$ & 17 & 1 \\
$21-25$ & 51 & 17 \\
$26-30$ & 43 & 31 \\
$31-35$ & 32 & 25 \\
$36-40$ & 8 & 20 \\
$41-45$ & 1 & 1 \\
$46-50$ & 1 & - \\
Not known & 1 & - \\
\hline
\end{tabular}


Table II shows distribution according to weight and height for age. It is apparent that few of the children were severely stunted and that the deficit in most of those showing subnormal growth was in the mild to moderate subnormal range. The distributions of weight and height were similar to those of previous samples selected as representative of the health district.

Table III includes selected social characteristics of the sample. There were few mothers under 20 years of age, and all families comprised five or more persons - a natural outcome of the selection criteria of two siblings, neither being firstborn. The sample was clearly a low income group; they spent, on the average, $70 \%$ of their income on food. Living conditions were extremely crowded. About half the mothers were illiterate or nearly illiterate.

\section{Simple Bivariate Relationships}

SPECIFIC FAMILY Characteristics WITH Weight/ $\frac{2}{8}$ AgE, Height/AgE Table IV shows the relationships ? found between family social characteristics and $\overrightarrow{\vec{D}}$ weight/age and height/age percentages (Note: Table IV should be read comparing social categories (rows) not columns).

Weight/age and height/age were found to be significantly related to family food expenditure, over-crowding, sanitary conditions of dwelling, family size and spacing, mother's age, parental newspaper reading, and aspirations for children.

Monthly food expenditure. Clear differences were found between children whose families spent less than 700 pesos per month on food (US\$35) and those who spent more than 700 pesos. It is interesting

TABLE IV

FAMILY CHARACTERISTICS RELATED TO WEIGHT/AGE AND HEIGHT/AGE

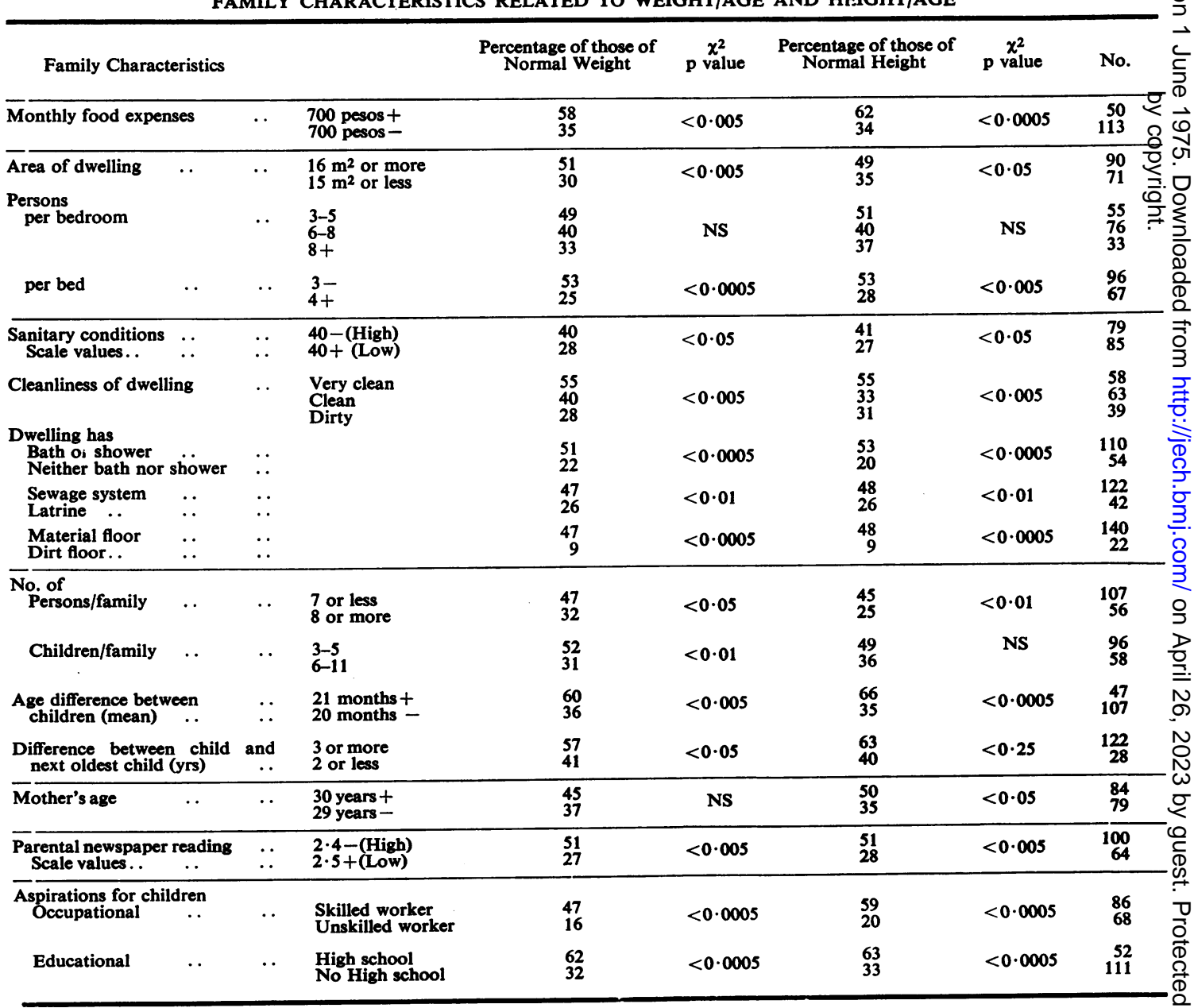


that the average monthly income of families with children of subnormal growth was $\$ 36$.

Crowding. Area of family dwelling, persons per bedroom, and persons per bed all showed highly significant relationships with weight/age and height/ age. The greater the crowding, the lower the incidence of normal physical growth.

Sanitary conditions. It is clear that better sanitary conditions were related to fewer children with weight and height deficits. Table IV shows findings concerning bath, sewage disposal, cleanliness, and condition of flooring, as well as the overall sanitary conditions.

Family size and spacing. Smaller families had a higher percentage of children with normal weight and height. The percentage of children with normal weight and height dropped considerably in a family with six or more children. These findings confirm those of Wray and Aguirre (1969), who also found six children to be a pivotal point for the effects of family size upon physical growth.

The findings clearly showed that the greater the spacing between births, the greater the prevalence of children of normal weight and height. In terms of the average interval between children in the family, the greatest difference was between those averaging $\mathbf{2 1}$ or more months and 20 or less months difference in age.

Mother's age. Mother's age was found to be significantly related to height but not to weight. Mothers aged over 30 years had a higher percentage of children of normal height. This finding seems to be contrary to what might be expected, especially since most of the mothers were aged 20-40 years and family size is positively associated with mother's age. Mother's age was not associated with socioeconomic status, or rural/urban origin, and, even within categories of family size, mothers of less than 30 years showed a tendency towards having a lower percentage of children of normal weight and height.

Parental newspaper reading. Parents with higher levels of newspaper reading had a significantly higher percentage of children with normal weight and height.

Aspirations for children. Parents who wanted their children to be skilled workers and attend high school had a much higher percentage of children with normal weight and height than parents with lower aspirations for their children. The relationship of parental attitude to physical growth was noted by Kallen (1971).
Socioeconomic Status and Weight/Age, Height/AGE Clear differences were found in levels of physical growth between the upper and lower socioeconomic groups (Table V). The upper group had a much higher percentage of children with normal weight and height for age. Furthermore, average weight/age and height/age for the upper socioeconomic group fell above the limits for normal physical growth, while average weight/age and height/age for the lower group fell within the mildly deficient range.

TABLE V

DIFFERENCES IN WEIGHT/AGE AND HEIGHT/AGE BETWEEN SOCIOECONOMIC LEVELS

\begin{tabular}{|c|c|c|c|}
\hline \multirow[b]{2}{*}{ Standard } & & \multicolumn{2}{|c|}{ Socioeconomic Level } \\
\hline & & $\begin{array}{l}\text { Lower Level }(n=64) \\
\text { (factor score } 2 \cdot 40-\text { ) }\end{array}$ & $\begin{array}{l}\text { Upper Level }(n=100) \\
\text { (factor score } 2 \cdot 41+)\end{array}$ \\
\hline $\begin{array}{l}\text { Weight/Age } \\
\text { Children } \\
\text { above } 90 \% \\
\text { Mean. } \\
\text { S D .. }\end{array}$ & $\begin{array}{l} \\
\cdots \\
\cdots\end{array}$ & $\begin{array}{l}\% \\
20 \\
78 \cdot 3 \\
13 \cdot 4\end{array}$ & $\begin{array}{l}\% \\
55 \\
90 \cdot 0 \\
13 \cdot 8\end{array}$ \\
\hline $\begin{array}{l}\text { Height/Age } \\
\text { Children } \\
\text { above 95\% } \\
\text { Mean.. } \\
\text { S D .. }\end{array}$ & . & $\begin{array}{l}23 \\
90 \cdot 0 \\
5 \cdot 17\end{array}$ & $\begin{array}{l}57 \\
95 \cdot 4 \\
5 \cdot 77\end{array}$ \\
\hline
\end{tabular}

To study the pattern of the relationship between socioeconomic level and physical growth, the five socioeconomic categories were compared for levels of weight/age (Figs. 1 and 2, Table VI). When the lower three categories $(1,2$, and 3$)$ were compared, weight and height deficits decreased with higher socioeconomic status. But in the upper socioeconomic range, comparing categories 3,4 , and 5

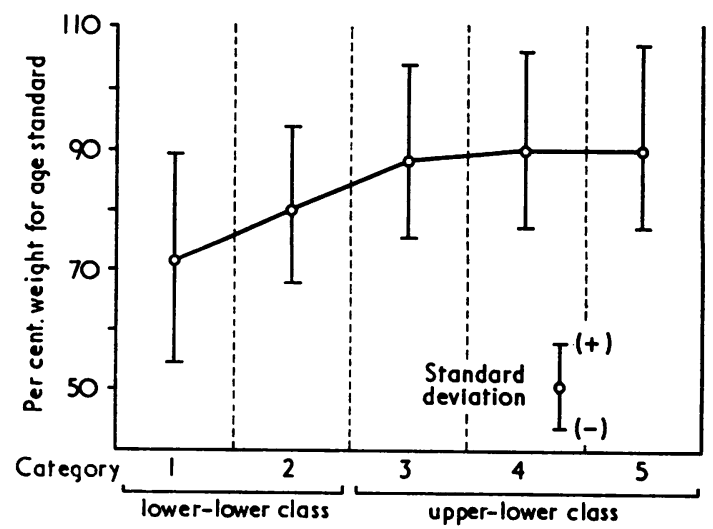

Fig. 1. Socioeconomic status as related to weight percentage for age. Socioeconomic status factor scores:
$\mathrm{N}=164 \mathrm{O}=$ category (mean) 
TABLE VI

WEIGHT/AGE AND HEIGHT/AGE BY SOCIOECONOMIC CATEGORY WEIGHT*

\begin{tabular}{|c|c|c|c|c|c|c|c|c|c|c|c|c|}
\hline $\begin{array}{c}\text { Socioeconomic } \\
\text { Category }\end{array}$ & Mean \% & S D & n & $\%$ & & $9 \%$ & & $\%$ & & $\%$ & $\mathbf{n}$ & $\%$ \\
\hline $\begin{array}{l}1 \\
2 \\
3 \\
4 \\
5\end{array}$ & $\begin{array}{l}73 \\
79 \\
88 \\
91 \\
91\end{array}$ & $\begin{array}{l}16.0 \\
13.4 \\
13.2 \\
13.6 \\
13.8\end{array}$ & $\begin{array}{r}1 \\
12 \\
29 \\
18 \\
8\end{array}$ & $\begin{array}{l}11 \\
22 \\
51 \\
60 \\
61\end{array}$ & $\begin{array}{r}0 \\
10 \\
12 \\
3 \\
3\end{array}$ & $\begin{array}{l}00 \\
18 \\
21 \\
10 \\
23\end{array}$ & $\begin{array}{r}3 \\
19 \\
11 \\
8 \\
2\end{array}$ & $\begin{array}{l}33 \\
34 \\
19 \\
19 \\
15\end{array}$ & $\begin{array}{r}5 \\
14 \\
5 \\
1 \\
0\end{array}$ & $\begin{array}{r}56 \\
25 \\
25 \\
3 \\
0\end{array}$ & $\begin{array}{r}9 \\
55 \\
57 \\
30 \\
13\end{array}$ & $\begin{array}{l}100 \\
100 \\
100 \\
100 \\
100\end{array}$ \\
\hline \multirow[t]{3}{*}{ Total } & & & 68 & & 28 & & 43 & & 25 & & 164 & \\
\hline & & & \multicolumn{8}{|c|}{ HEIGHT* } & & \\
\hline & & & \multicolumn{2}{|c|}{$\mathrm{n}^{95 \%+} \%$} & $\begin{array}{l}90 \\
\text { n }\end{array}$ & $4 \%$ & \multicolumn{2}{|c|}{$\begin{array}{l}85 \%-89 \% \\
\mathrm{n}\end{array}$} & \multicolumn{2}{|c|}{$\begin{array}{l}75 \%-84 \% \\
\mathrm{n} \quad \% \\
\end{array}$} & & \\
\hline $\begin{array}{l}1 \\
2 \\
3 \\
4 \\
5\end{array}$ & $\begin{array}{l}87 \cdot 5 \\
90.4 \\
94.8 \\
95.9 \\
96 \cdot 3\end{array}$ & $\begin{array}{l}6 \cdot 9 \\
5 \cdot 5 \\
5 \cdot 1 \\
4 \cdot 3 \\
6 \cdot 2\end{array}$ & $\begin{array}{r}1 \\
14 \\
30 \\
16 \\
8\end{array}$ & $\begin{array}{l}11 \\
25 \\
53 \\
53 \\
62\end{array}$ & $\begin{array}{r}1 \\
14 \\
19 \\
12 \\
5\end{array}$ & $\begin{array}{l}11 \\
25 \\
33 \\
40 \\
38\end{array}$ & $\begin{array}{r}5 \\
20 \\
5 \\
2 \\
0\end{array}$ & $\begin{array}{r}56 \\
36 \\
9 \\
7 \\
0\end{array}$ & $\begin{array}{l}2 \\
7 \\
3 \\
0 \\
0\end{array}$ & $\begin{array}{r}22 \\
12 \\
5 \\
0 \\
0\end{array}$ & $\begin{array}{r}9 \\
55 \\
57 \\
30 \\
13\end{array}$ & $\begin{array}{l}100 \\
100 \\
100 \\
100 \\
100\end{array}$ \\
\hline Total & & & 69 & & 51 & & 32 & & 12 & & 164 & \\
\hline
\end{tabular}

*Compared with Colombian age/sex standards

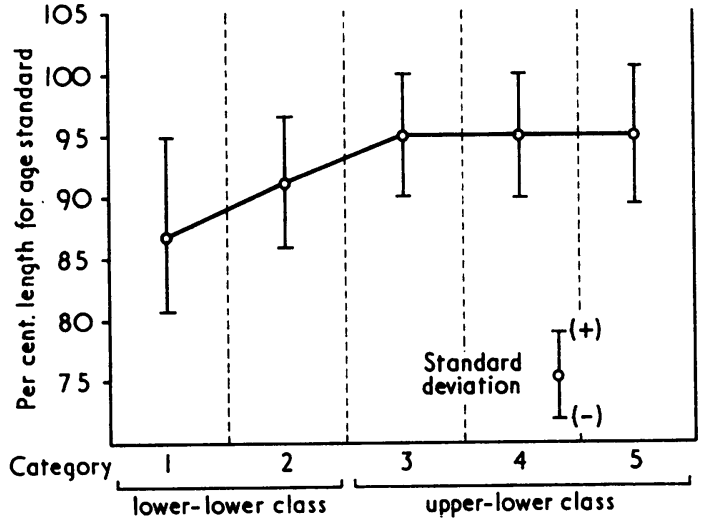

Fig. 2. Socioeconomic status as related to length percentage for age. Socioeconomic status factor scores:

$\mathrm{N}=164 \quad \mathrm{O}=$ category (mean)

higher socioeconomic status was not associated with significant increases in level of weight/age and height/ age (Figs. 1 and 2). This was true for both mean levels and prevalence of moderate and serious deficits (Table VI). In short, there appeared to be a threshold effect in the relationship between socioeconomic status and physical growth.

Correlation and Multiple Regression ANAlyses

Ten social variables were selected for correlation and regression analysis. These variables were chosen as being representative of the seven social characteristics associated with weight and height, as shown in Table IV. Table VII shows the relationship of these ten variables to weight and height in both correlation and multiple regression analysis.

All the variables were found to be significant correlated with both weight/age and height/age, except for 'number of persons in family'. The association can be described as moderate, as the correlations ranged from $0 \cdot 21$ to $0 \cdot 37$. The degree of correlation was consistently higher with height/ age than with weight/age.

When the ten variables were used in multiple regressions to predict weight/age and height/age, the pattern of associations changed significantly. Only sanitary conditions, family size, age difference between children, and occupational aspirations were found to be significantly associated with weight/age. The ten variables explained $30 \%$ of variance in weight/age. Significant associations were found for sanitary conditions, age difference between children, mother's age, and family food expenditure when predicting height/age percentage. The ten variables explained $39 \%$ of the variance in $N$ height/age.

A second multiple regression analysis was done, using weight/age and height/age scores, adjusted for the effect of socioeconomic status (Table VII). Scores were derived by first regressing the socioeconomic status on weight/age and height/age, and then computing residual scores for weight/age and height/age. A somewhat different pattern of relationships resulted from this second regression analysis where socioeconomic status effects were 
TABLE VII

SPECIFIC SOCIAL CHARACTERISTICS THAT ARE ASSOCIATED WITH WEIGHT/AGE PERCENTAGES AND HEIGHT/AGE PERCENTAGES BEFORE AND AFTER ADJUSTING FOR EFFECT OF SOCIOECONOMIC STATUS

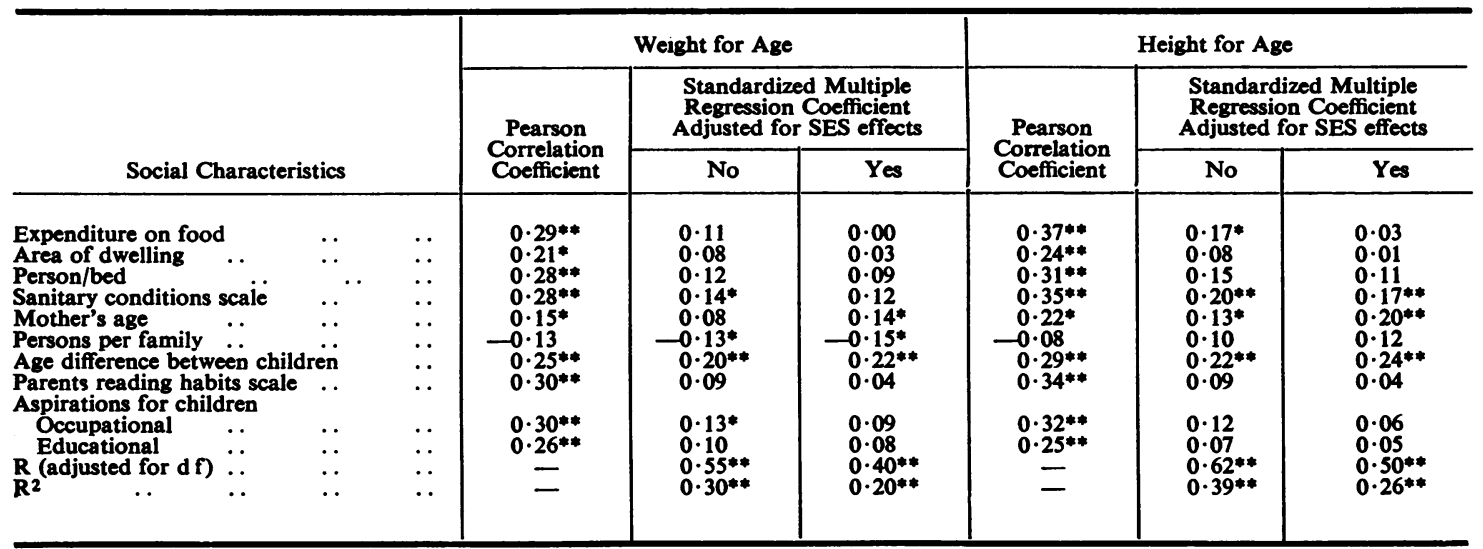

$\mathrm{n}=164$

df $=154$

$* \mathbf{P}<0.05$ one-tailed $t$ test

$* * \mathrm{P}<0.01$ one-tailed $t$ test

controlled. Mother's age and age differences between children were significantly associated with both weight/age and height/age. Family size was related to weight/age, while sanitary conditions were related to height/age.

The reason that only four of the social characteristics showed independent contributions to weight and height differences was that the other six social characteristics were highly correlated with socioeconomic status and thus intercorrelated with each other (Table VIII). Mother's age, family size, and age difference between children each made an independent contribution to weight/age or height/age differences because these three variables correlated least with the other characteristics. Sanitary conditions were responsible for significant variations in height/age because of their high initial correlation, even though these were slightly more intercorrelated than mother's age, age difference, or family size.

\section{Discussion AND Summary}

The findings indicate that expenditure on food, sanitary conditions, crowding, mother's age, family size, age spacing of the children, parents' reading habits, and aspirations for children are all associated with differences in levels of physical growth. These social characteristics probably affect the child's physical growth by influencing the incidence of infectious disease and its dietary intake. A greater incidence of infectious diseases would seem to be influenced by poor sanitary conditions, small and crowded dwellings, and crowded sleeping facilities. Availability and distribution of food within the family would seem to be highly affected by food expenditure and age spacing of the children. Both disease and food intake can be affected by family size. It is not clear how disease and food intake can be related to mother's age after family size is statistically controlled, as the results offered little clue as to the actual importance of mother's age for physical growth.

The associations found between family social characteristics and physical growth confirm findings from other countries. Even though a highly selected sample was used in the present study, the high level of agreement between the present and previous findings indicates a degree of generalizability beyond urban Colombia. The family social characteristics studied thus appear to be associated with physical growth, irrespective of cultural or national setting.

It should be noted, however, that the highly selected nature of the sample may have altered the findings to some extent, in comparison with the population as a whole. For instance, the necessity of having at least three children in the family, excluded from the sample those families with fewer children and tended to exclude younger mothers, and probably resulted in more families with closely spaced births, since birth spacing has been commonly found to be negatively associated with family size. Reducing the range and variance of family size and birth spacing probably resulted in an underestimate of the relationship of these two characteristics to physical growth, as better physical growth has 


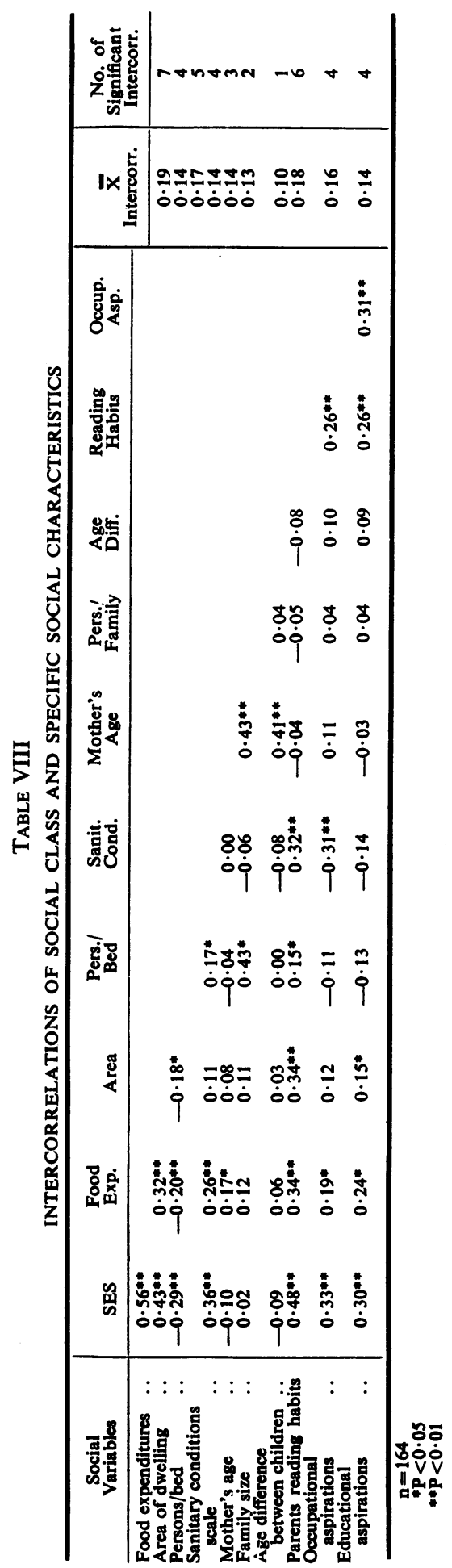


repeatedly been found to be associated with smaller families and longer intervals between births. Past research has found mother's age to be negatively associated with physical growth of the child, while the present study found mother's age to be positively associated with physical growth. This contradiction may be due to the fact that few mothers in the sample were under 20 years of age. Studies have repeatedly shown that mothers under 20 and over 35 years have children with poorer physical growth. Thus the virtual elimination of young mothers in the present sample may have resulted in the reversal of the relationship between mother's age and physical growth.

The present findings confirm, in a sample of infants, associations which had previouly been found among pre-school and school-age children. This indicates that the social characteristics which were studied can affect physical growth beginning in the earliest years of life and continuing through childhood.

Family size, age spacing of children, and mother's age all showed a relationship with physical growth differences, independent of socioeconomic status and of each other. This finding should be understood in the context of the Bogotá population. A recent survey of women took representative samples from seven large Latin American cities; $60 \%$ to $70 \%$ of each sample were classified as 'low class'. Women in Bogotá knew least about birth control, had the next-highest birth rate and desired family size, and had the highest level of illiteracy (Hass, 1972). This may account for the lack of relationship between socioeconomic status and family size, age spacing, and age of mothers of young children. Where literacy is higher and information on birth control is more readily available, increasing socioeconomic status may be accompanied by smaller families, greater spacing between births, and fewer births later in the mother's reproductive period.

Low food expenditure, crowded living conditions, low level of newspaper reading, and low aspirations were all found to be related to poor physical growth as part of an overall effect of socioeconomic status. This is not surprising, as these social characteristics have frequently been cited as being components of the vicious cycle of social deprivation. However, it is significant that the above associations were found not when comparing the lower class with the upper class, but when comparing families at the lower and upper ends of the lower class in Bogotá. This supports Kallen's (1971) contention that the Latin American lower classes are far from homogeneous, and that important family differences exist within the lower class that have an effect on the growth and development of children. The upper socioeconomic group in the sample showed average physical growth levels which fell within the normal range. This is understandable when one considers the distribution of families according to social class in Colombia and the variation that exists within the lower class. Of the Bogotá population $60 \%$ to $70 \%$ are classified as 'lower class' (Young, 1974). Within the Colombian context, these $60 \%$ to $70 \%$ are clearly 'lower class' in terms of income, education, occupation, dwelling, and disposable income in comparison particularly with the Colombian middle and upper classes. However, income varies widely within the large lower class and, as the present study indicates, part of the lower class clearly has resources to protect its children adequately against physical growth deficits. Moreover, the results indicated that, once a certain socioeconomic level is reached within the lower class, improvement in socioeconomic status does not bring with it a substantial increase in physical growth level even though this is suboptimal.

In summary, reproductive characteristics of the family and sanitary conditions of the household appeared to have affected physical growth, independent of socioeconomic status and of each other. Crowding, food expenditure, aspirations, and reading habits were related to physical growth as part of an overall effect of socioeconomic differences. The findings also suggested that for physical growth of children in Latin American urban populations socioeconomic differences within the lower class may be more important than differences between classes.

The authors gratefully appreciate the help of Alvaro Amézquita in data processing and the comments of Robert Reed and Jean-Pierre Habicht on earlier versions of this paper.

Requests for reprints: N. Christiansen, Research Project on Malnutrition and Mental Development, Apartado Aéreo 91186, Bogotá, Colombia, South America.

\section{REFERENCES}

Berry, W. T. C., and Cowin, P. J., (1954). Conditions associated with growth of boys, 1950-51, Brit. med. J., $1,847$.

Chase, H. P., and Martin, H. P. (1970). Undernutrition and child development. New Engl. J. Med., 282, 933.

Christiansen, N., and Dragastin, S. (1971). Unpublished data.

Cobos, F., Latham, M., and Stare, F. J. (1972). Will improved nutrition help to prevent mental retardation? Prev. Med., 1, 185. 
Cravioto, J., Birch, H. G., De Licardie, E. R., and Rosales, L. (1967). The ecology of infant weight gain in a pre-industrial society. Acta paediat. scand., $56,61$.

HASs, P. H. (1972). Maternal role incompatibility and fertility in urban Latin America. J. soc. Iss., 28, 2.

Kallen, D. J. (1971). Nutrition and society. J. Amer. med. Ass., 215, 94.

MORA, J. O. (1971). Unpublished data.

Pollit, E., and Ricciutti, H. (1968). Unpublished data.

SToch, M. B., and SMYTHE, P. M. (1967). The effects of undernutrition during infancy on subsequent brain growth and intellectual development. S. Afr. med. J., 41, 1027.
WEIR, J. B. DE V. (1952). The assessment of growth of schoolchildren with special reference to secular changes. Brit. J. Nutr., 6, 19.

Wray, J. D., and Aguirre, A. (1969). Protein-calorie malnutrition in Candelaria, Colombia, I. Prevalence; social and demographic causal factors. J. trop. Pediat., $15,76$.

YouNG, H. B. (1970). Socioeconomic factors in child development. Bibl. 'Nutr. et Dieta' (Basel), No. 14, 43.

(1974). Estudio de estratificacion socioeconomica $\vec{\circ}$ de los barrios de Bogotá D. E. Departmento Administrativo de Planeacion Distrital, Bogotá. 